\title{
Rapid peripheral arterial cannulation for extracorporeal life support with unimpaired distal perfusion
}

\author{
Stefanos Demertzis, MD, PhD, and Thierry Carrel, MD, PhD, Bern, Switzerland
}

Installation of lifesaving arteriovenous extracorporeal support during major hemodynamic instability requires rapid cannulation, usually of a femoral artery and vein. Peripheral ischemia is one of the most severe complications of peripheral arterial cannulation. We describe a novel and easy technique that allows for rapid cannulation and subsequent full restoration of distal artery perfusion when lifesaving perfusion is initiated.

\section{CLINICAL SUMMARY}

Surgical cutdown and rapid exposure of the inguinal vessels is performed. The anterior wall of the common femoral artery is cleaned from surrounding tissue, and punctured with an 18-gauge hollow needle. A guide wire is advanced into the lumen, followed by a 7F dilator. An arterial cannula with a mandrin is chosen (EOPA dilator tip arterial cannula; Medtronic, Inc, Minneapolis, Minn). A presealed short vascular prosthesis (Gelseal, Vascutek Ltd, Renfrewshire, United Kingdom) with an appropriate diameter to include the arterial cannula is chosen, slightly beveled at its presumptive distal end, and passed over the cannula. Then the cannula is advanced over the wire into the arterial lumen (Figure 1, A). Backflow is confirmed, and the cannula is temporarily secured to the skin with a suture.

The femoral vein is cannulated in similar fashion (without the vascular prosthesis), advancing a multiperforated long cannula up to the right atrium. A purse-string suture around the cannulation site is added later.

When extracorporeal perfusion is stable and the patient's condition is under control, the vascular prosthesis around the cannula is lowered onto the femoral artery (Figure 1, $B$ ). The prosthesis is anastomosed to the artery with a running suture (monofilament 5-0 thread with a BB needle), taking meticulous care to not stitch the wall of the arterial cannula. Excessive bleeding can be controlled by a rubber loop passed around the proximal femoral artery. The arteriotomy can

\footnotetext{
From the Department of Cardiovascular Surgery, Inselspital, University Hospital Bern and University of Bern, Bern, Switzerland.

Disclosures: Authors have nothing to disclose with regard to commercial support.

Received for publication April 26, 2010; revisions received May 15, 2010; accepted for publication May 24, 2010; available ahead of print Sept 10, 2010.

Address for reprints: Stefanos Demertzis, MD, PhD, Department of Cardiovascular Surgery, University Hospital Bern, Inselspital, CH-3010 Bern, Switzerland (E-mail: stefanos.demertzis@insel.ch).

J Thorac Cardiovasc Surg 2011;141:1080-1

$0022-5223 / \$ 36.00$

Copyright $($ C 2011 by The American Association for Thoracic Surgery doi:10.1016/j.jtcvs.2010.05.047
}

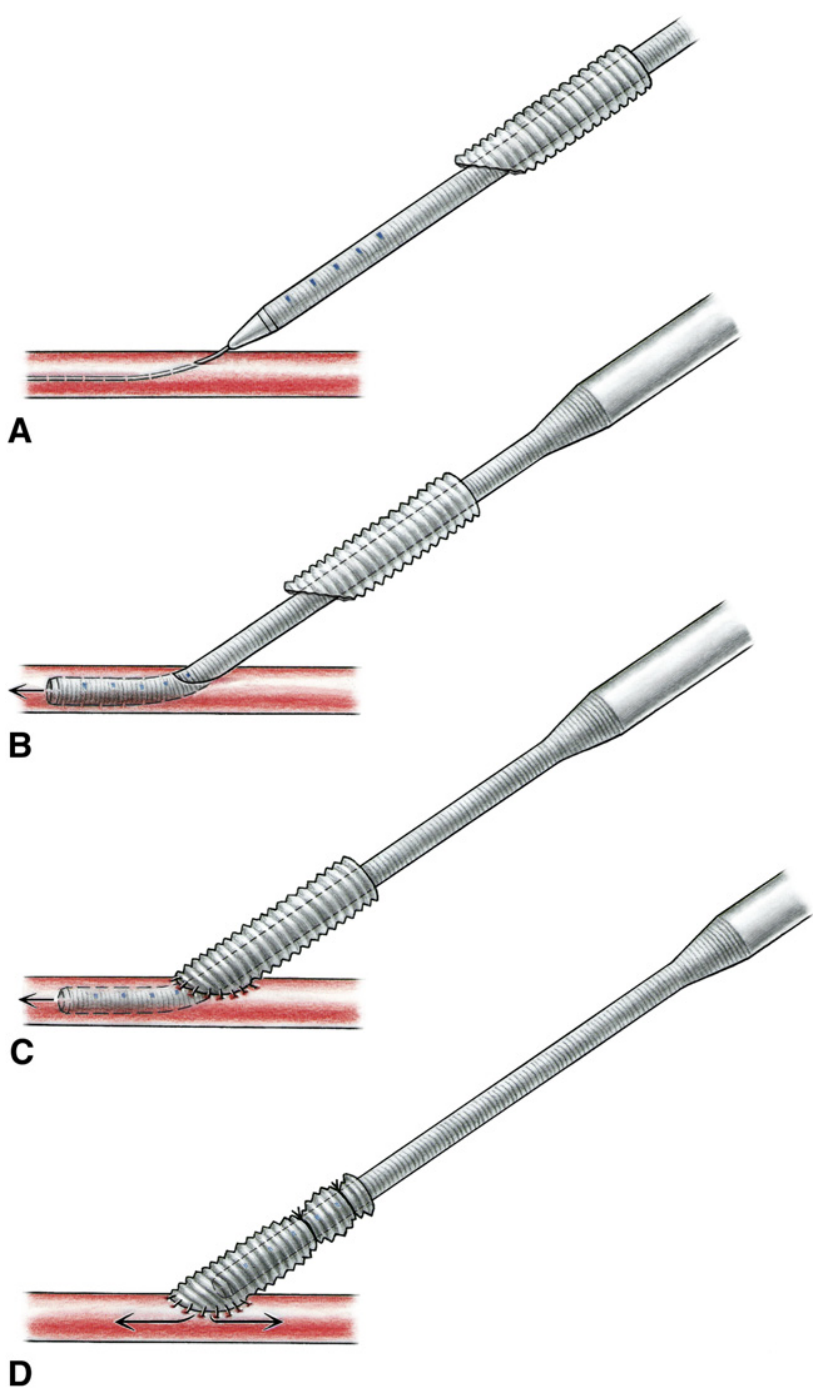

FIGURE 1. The 4 major steps (A-D) of the new cannulation technique (see text for detailed description). Perfusion (single arrow) is initiated immediately after cannulation (B). Distal perfusion (2 arrows) is restored after withdrawal of the cannula into the vascular prosthesis (D).

be slightly extended to accommodate the prosthesis. The anastomosis is tightened by carefully pulling the suture with hooks (Figure 1,C). Now the arterial cannula can be withdrawn carefully, positioning its distal end within the prosthesis at the level of the anastomosis. Full distal limb perfusion is now restored (Figure 1, D). Distal hyperperfusion is avoided by orientation of the anastomosis. Decannulation and reconstruction of the femoral artery is easy and safe, leaving a very short prosthetic stump on the artery, 
thereby ensuring adequate lumen diameter with no residual stenosis.

We applied this technique in 3 patients undergoing cardiopulmonary resuscitation who required life-saving extracorporeal membrane oxygenation support. Initiation of perfusion was rapid (14 \pm 3 minutes from incision to perfusion). Peripheral perfusion was easily detectable with vascular Doppler examination. In one case an inflow/outflow mismatch was suspected because the limb became slightly edematous after 12 hours of perfusion. In this case the prosthesis was not beveled, resulting in a noncommitted $90^{\circ}$ anastomosis. The potentially higher distal flow of this configuration in combination with the partially occluded femoral vein (through the venous cannula) could have contributed to this problem, which resolved after decannulation. The other patients did not have any perfusion-related complications (extracorporeal membrane oxygenation was discontinued after 74 and 54 hours, respectively).

\section{DISCUSSION}

Peripheral ischemia distal to the cannulation site is a severe complication of femoral arterial cannulation for extracorporeal life support. ${ }^{1,2}$ When the patient's hemodynamic condition is stable enough, suturing a beveled prosthetic graft to the artery and placing the distal end of the cannula at the level of the anastomosis avoids lumen occlusion by the cannula, thereby preventing any distal malperfusion. ${ }^{2}$ In dramatically critical situations rapid initiation of the lifesaving perfusion has first priority. With the described technique, perfusion can be initiated rapidly. Suturing of the side graft is slightly postponed and does not require any interruption of the perfusion. Beveling of the prosthesis allows for a more favorable flow direction toward the heart, potentially avoiding preferential distal flow.

There are also alternative techniques. ${ }^{3-5}$ Those with published clinical applications have in common the introduction of an additional catheter in the distal artery, which is then connected to the extracorporeal circuit. These techniques also allow for a rapid initiation of perfusion. However, the effective distal perfusion flow can be low because it is determined by the resistance of the connection of the perfusion catheter to the circuit and of the diameter of the catheter itself. In addition, after decannulation, the femoral arteries are left with 2 openings and potential thrombus formation between them, requiring careful vascular reconstruction.

In summary, we present a rapid femoral arterial cannulation technique for extracorporeal life support, which allows for unimpaired distal limb perfusion.

\section{References}

1. Gates JD, Bichell DP, Rizzo RJ, Couper GS, Donaldson MC. Thigh ischemia complicating femoral vessel cannulation for cardiopulmonary bypass. Ann Thorac Surg. 1996;61:730-3.

2. Vander Salm TJ. Prevention of lower extremity ischemia during cardiopulmonary bypass via femoral cannulation. Ann Thorac Surg. 1997;63:251-2.

3. Greason KL, Hemp JR, Maxwell JM, Fetter JE, Moreno-Cabral RJ. Prevention of distal limb ischemia during cardiopulmonary support via femoral cannulation. Ann Thorac Surg. 1995;60:209-10.

4. Madershahian N, Nagib R, Wippermann J, Strauch J, Wahlers T. A simple technique of distal limb perfusion during prolonged femoro-femoral cannulation. J Card Surg. 2006;21:168-9.

5. Magovern JA, Fonger JD, Wang DHJ, Kopilec D, Trumble DR, Smith DE. A femoral artery cannula that allows distal blood flow. J Thorac Cardiovasc Surg. 2005 130:684-6.

\title{
Absorbable pulmonary arterial banding: An optimal strategy for muscular or residual ventricular septal defects
}

\author{
Norihiko Oka, MD, PhD, Christian P. Brizard, MD, Matthew Liava'a, MBChB, and \\ Yves d'Udekem, MD, PhD, Melbourne, Australia
}

\footnotetext{
From the Department of Cardiac Surgery of the Royal Children's Hospital, the Department of Paediatrics of the University of Melbourne, and the Murdoch Children's Research Institute, Melbourne, Australia.

Disclosures: Authors have nothing to disclose with regard to commercial support.

Received for publication Dec 22, 2009; revisions received Feb 28, 2010; accepted for publication April 10, 2010; available ahead of print Sept 3, 2010.

Address for reprints: Yves d'Udekem, MD, PhD, Royal Children's Hospital, Flemington Rd, Parkville, Victoria 6009, Australia (E-mail: yves.dudekem@rch. org.au).

J Thorac Cardiovasc Surg 2011;141:1081-2

$0022-5223 / \$ 36.00$

Crown Copyright (C) 2011 Published by Elsevier Inc. on behalf of The American Association for Thoracic Surgery

doi:10.1016/j.jtcvs.2010.04.044
}

With conventional pulmonary arterial banding (PAB), a second surgical procedure to remove the band is compulsory, regardless of eventual ventricular septal defect (VSD) closure. Use of an absorbable PAB abolishes this requirement. ${ }^{1}$

In 2003, we started to use a custom absorbable PAB made of polydioxanone, mainly for patients in whom muscular and residual VSDs were expected to close spontaneously. Polydioxanone is a widely used biodegradable polymer that is known to keep $35 \%$ of its mechanical strength for about 3 weeks and to degrade completely in about 6 months. We hypothesized that a PAB made of this absorbable 